\title{
Have you seen a skinny alligator in south Florida?'
}

\author{
Michiko Squires, Avishka Godahewa, Justin Dalaba, Laura A. Brandt, and Frank J. Mazzotti²
}

Alligator biologists and natural resource managers need your help! Be a citizen scientist and help track alligator health and body condition throughout the greater Everglades ecosystem.

There has been an increase in reports of very skinny alligators, and help from the public is needed to better understand where and when this problem occurs. When visiting the Everglades, you can be a citizen scientist and help identify and document very skinny alligators. Carefully observe and photograph an alligator from a safe distance, then classify its body condition based on the guidelines below. In addition to the tools you have on hand (smartphone, binoculars, etc.), use this fact sheet as a simple way to classify the body condition of alligators.

\section{Why do we care?}

The American alligator (Alligator mississippiensis) plays an important role in the Everglades. Alligators affect nearly all aquatic life in an ecosystem as top predators and help provide habitat for other animals as ecosystem "engineers." Without the holes and trails that alligators build, there would be fewer refugia, or hiding places, for fish and wading birds during the dry season, and without their nest mounds, there will be less of the high ground that land animals need during flooding in the Everglades. For more information on the importance of alligators in the Everglades, visit http://edis.ifas.ufl.edu/uw358.

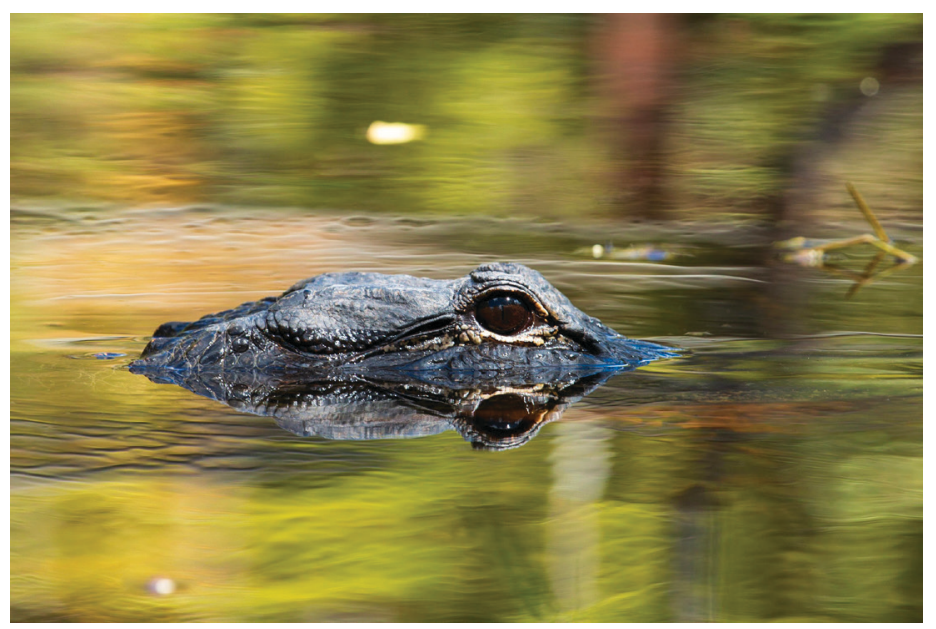

Figure 1. American alligator in the Everglades.

Credits: Justin Dalaba, UF/IFAS

In turn, alligators are also affected by their environment. Changes in depth, timing, and flow of freshwater can affect their health (indicated by relative fatness) and their abundance. Alligators' responses to these changes make them an effective indicator species: when their populations decline or when individual alligators look thin, it's a sign that their Everglades ecosystem would benefit from restoration of more natural patterns of water levels and flows.

The natural freshwater flow through the Florida Everglades is highly modified by artificial canals and levees (for more information, visit http://edis.ifas.ufl.edu/uw349). Monitoring ecological indicators like the American alligator tells

1. This document is WEC415, one of a series of the Department of Wildlife Ecology and Conservation, UF/IFAS Extension. Original publication date December 2019. Visit the EDIS website at https://edis.ifas.ufl.edu for the currently supported version of this publication.

2. Michiko Squires, wildlife biologist; Avishka Godahewa, wildlife biologist; Justin Dalaba, science writer and outreach coordinator; UF/IFAS Fort Lauderdale Research and Education Center; Laura A. Brandt, wildlife biologist, US Fish and Wildlife Service, Davie, FL; and Frank J. Mazzotti, professor, Department of Wildlife Ecology and Conservation, UF/IFAS Fort Lauderdale Research and Education Center; UF/IFAS Extension, Gainesville, FL 32611.

The information in this publication is available as a printable trifold brochure at http://edis.ifas.ufl.edu/pdffiles/UW/UW461.pdf

The Institute of Food and Agricultural Sciences (IFAS) is an Equal Opportunity Institution authorized to provide research, educational information and other services

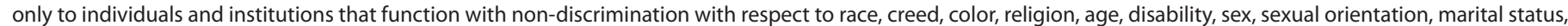

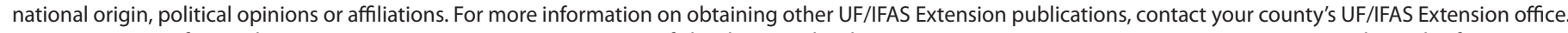
U.S. Department of Agriculture, UF/IFAS Extension Service, University of Florida, IFAS, Florida A \& M University Cooperative Extension Program, and Boards of County Commissioners Cooperating. Nick T. Place, dean for UF/IFAS Extension. 
managers how different areas of this large ecosystem are doing. This fact sheet serves as a guide on scoring alligator body condition and reporting sightings of very skinny alligators to researchers and managers.

Body condition describes an animal's overall physical health and provides insight into how an animal is coping with its environment. For the American alligator in the Everglades, critical environmental factors include water quality, prey availability, and water temperature. The use of a body condition scoring system (BCS) is a simple way to assess an alligator's body condition from a safe distance.

\section{How can you help?}

If you see a very skinny alligator:

1. Take a picture from a safe distance (recommended at least 20 feet).

2. Note the exact coordinates at the location (can drop a pin on smartphone map).

3. Add your observation to the Alligator Body Condition project on iNaturalist by visiting: https://www.inaturalist. org/projects/alligator-body-condition

Scan this QR code or visit https://www.inaturalist.org/ projects/alligator-body-condition to report sightings of very skinny alligators and help resource managers better understand this problem.

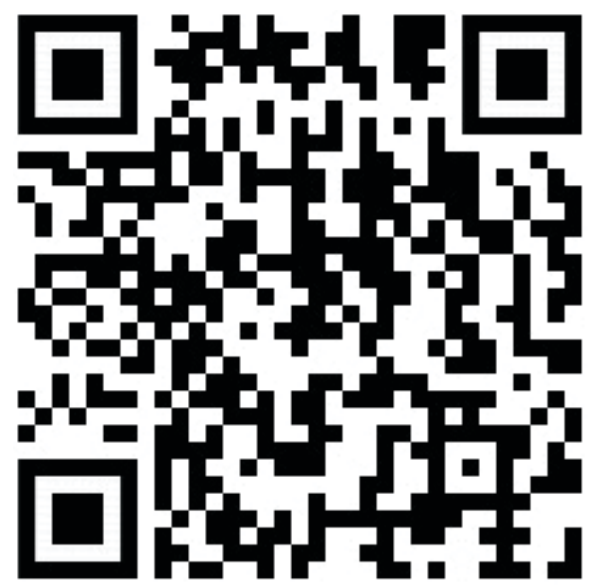

\section{For More Information Contact}

Frank J. Mazzotti

UF/IFAS Fort Lauderdale Research \& Education Center 3205 College Ave., Davie, FL 33314

Email: fjma@ufl.edu

http://crocdoc.ifas.ufl.edu/ 


\section{Body Condition Score}

The physical condition of alligators is an important clue to their health for a specific area. To make it easy for citizen scientists to report very skinny alligators in the Greater (BCS) from 1 to 3 , where 1 = very skinny (emaciated), 2 = thin or slender (usual for Everglades alligators), and $3=$ normal for their entire range. Everglades, biologists have developed a body condition score

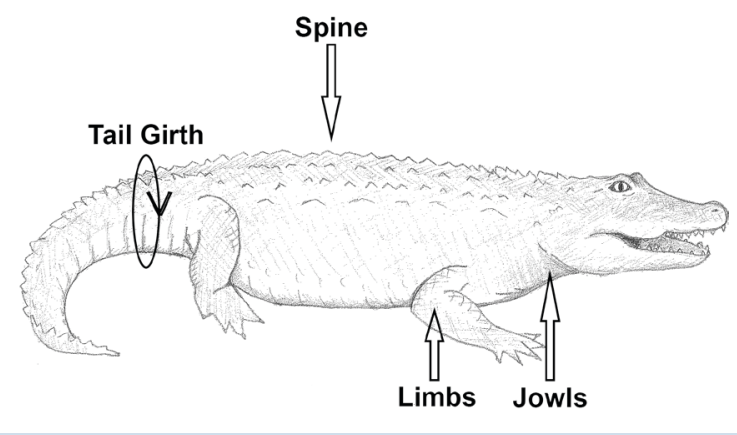

\section{BCS 01 -Emaciated}

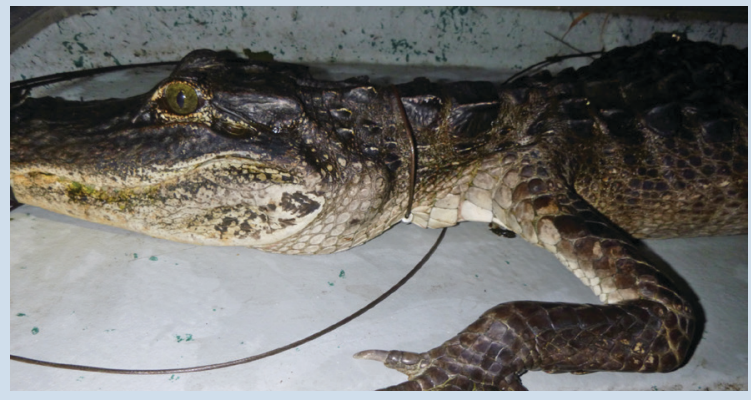

Shrunk jowls, thin neck, thin limbs

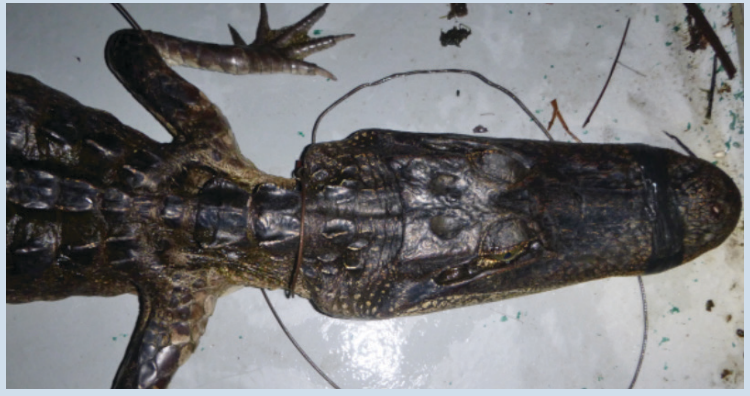

Very bony, visible spinal column

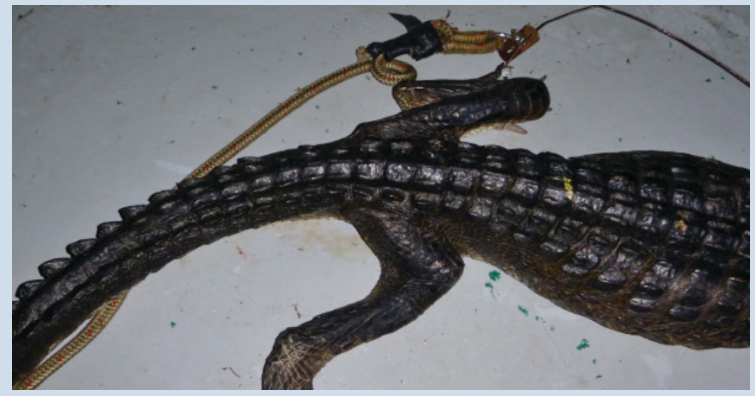

Very thin tail, and wrinkled skin

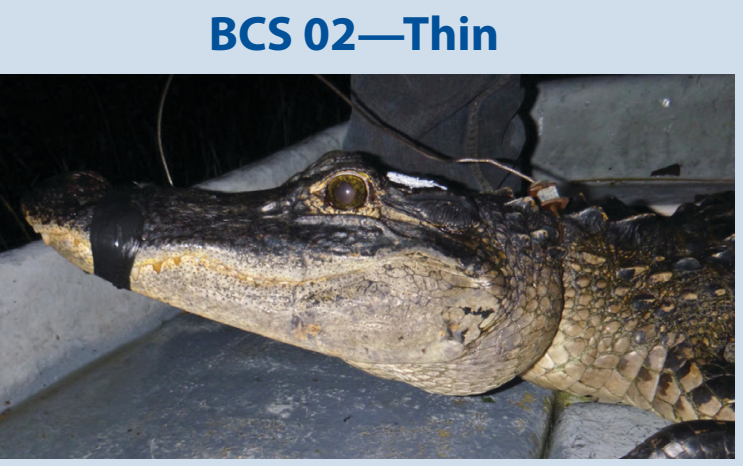

Lean jowls, thin neck, thin limbs

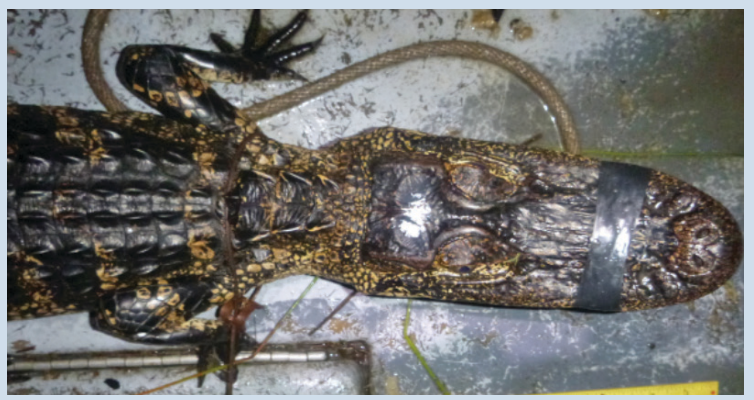

Barely visible spinal column

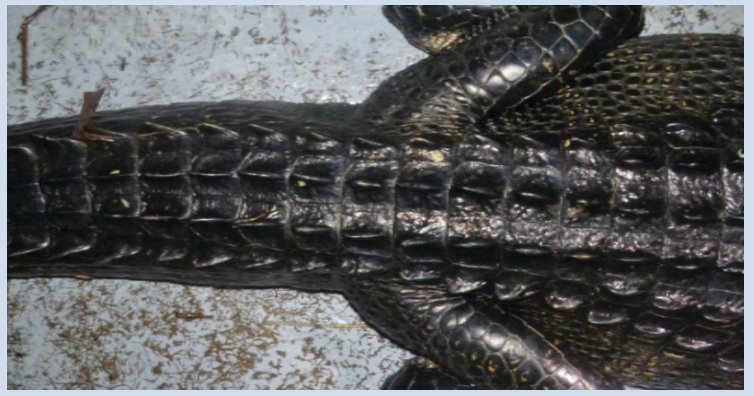

Lean tail and tail girth
- Limbs-Four total; two front and two rear legs

- Jowls-Lower cheek area between the end of the snout and front limbs

- Spinal column-Dorsal area between front and rear limbs

- Tail girth-Thickness of tail behind rear limbs

Energy reserves are stored as muscle and fat, especially in the jowls and base of the tail. Healthy alligators have full jowls and plump tails, while unhealthy alligators have shrunken jowls and thin tails.

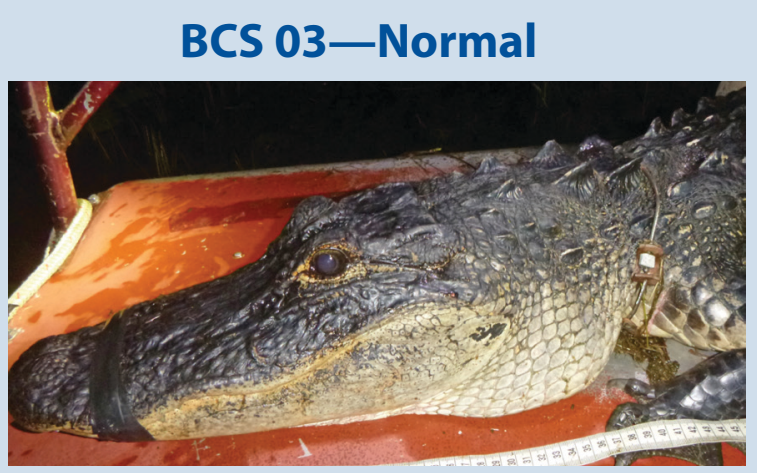

Full, fleshy and bulky jowls

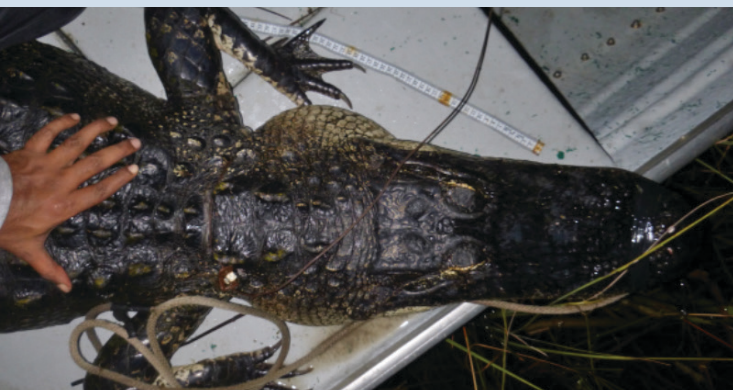

Muscular limbs, spinal column not visible

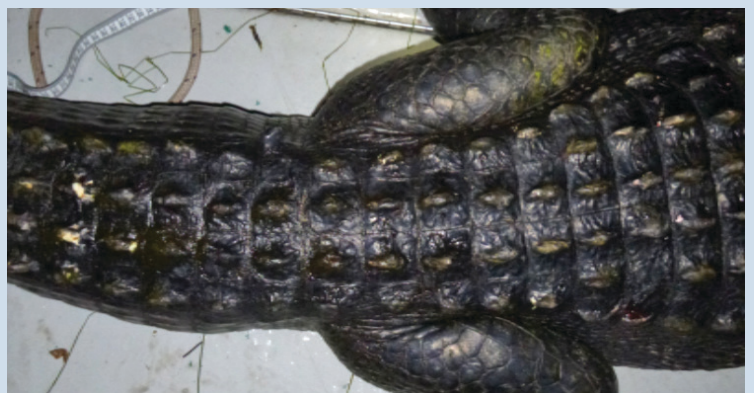

Plump tail and larger tail girth 